\title{
Immune Checkpoint Imaging in Oncology: A Game Changer Toward Personalized Immunotherapy?
}

\author{
Susanne Lütje ${ }^{1}$, Georg Feldmann ${ }^{2}$, Markus Essler ${ }^{1}$, Peter Brossart ${ }^{2}$, and Ralph A. Bundschuh ${ }^{1}$ \\ ${ }^{1}$ Department of Nuclear Medicine, University Hospital Bonn, Bonn, Germany; and ${ }^{2}$ Department of Internal Medicine 3, Center of \\ Integrated Oncology Cologne-Bonn, University Hospital Bonn, Bonn, Germany
}

\begin{abstract}
Immune checkpoint blockade represents a promising approach in oncology, showing antitumor activities in various cancers. However, although being generally far better tolerated than classic cytotoxic chemotherapy, this treatment, too, may be accompanied by considerable side effects and not all patients benefit equally. Therefore, careful patient selection and monitoring of the treatment response is mandatory. At present, checkpoint-specific molecular imaging is being increasingly investigated as a tool for patient selection and response evaluation. Here, an overview of the current developments in immune checkpoint imaging is provided.
\end{abstract}

Key Words: checkpoint blockade; molecular imaging; oncology; PET/CT

J Nucl Med 2020; 61:1137-1144

DOI: 10.2967/jnumed.119.237891

$\mathbf{T}$

he basic idea of cancer immunotherapy is to induce, potentiate, and revive antitumor responses originating from a patient's immune system. Depending on the number of mutations in cancer cells, immune cells are able to recognize and attack cancer cells. However, evasion of attack by the immune system is one of the hallmarks of cancer, leading to the development of tolerance (1). This process can be initiated by several mechanisms, including the upregulation of inhibitory immune checkpoint pathways, such as programmed cell death protein 1 (PD-1)/programmed deathligand 1 (PD-L1), or cytotoxic T-lymphocyte-associated protein 4 (CTLA-4) $(2,3)$. T-cell effector function can be downregulated by these pathways, potentially leading to tumors that evade immune surveillance. Immune checkpoint inhibitors targeting one of these pathways inhibit these immune escape mechanisms and thereby reactivate the immune system to recognize and destroy the tumor cells.

So far, several such immune checkpoint inhibitors have been registered and approved for cancer treatment, including antiCTLA-4 antibodies such as ipilimumab (4), anti-PD-1 antibodies such as nivolumab (Opdivo; Bristol-Myers Squibb) (5) or pembrolizumab (Keytruda; Merck Sharp \& Dohme) (6), and anti-PDL1 antibodies such as durvalumab (Imfinzi; AstraZeneca) (7),

Received Oct. 17, 2019; revision accepted Jan. 3, 2020.

For correspondence or reprints contact: Susanne Lütje, Department of Nuclear Medicine, University Hospital Bonn, Venusberg-Campus 1, 53127 Bonn, Germany.

E-mail: susanne.luetje@ukbonn.de

Published online Jan. 10, 2020.

COPYRIGHT (C 2020 by the Society of Nuclear Medicine and Molecular Imaging. avelumab (Bavencio; 2019 EMD Serono) (8), or atezolizumab (Tecentriq; Genentech) (9). Encouraging results have been reported in various malignancies including melanoma, breast cancer, head and neck cancer, and non-small cell lung cancer (NSCLC), for which immune checkpoint blockade is currently complementing classic cytostatic chemotherapy as a first-line therapy in certain subsets of patients (10). Despite impressive clinical responses in a series of malignancies so far, the reality remains that these responses are limited to defined patient subgroups. Consequently, nonresponding patients may unnecessarily be exposed to these regimens posing the risk of potential associated adverse effects, which may include severe immune-related adverse events, such as pneumonitis, colitis, or pancreatitis (11-13). Therefore, there is a pressing need for biomarkers to identify patients who will respond to and profit from immune checkpoint blockade in oncology.

\section{IMMUNE CHECKPOINT BLOCKADE}

At present, immune checkpoint blockade is clinically most commonly used for two pathways, one interfering with the PD-1/ PD-L1 axis and the other one involving CTLA-4. Therefore, first, a short overview of these 2 pathways is presented.

\section{PD-1/PD-L1 Pathway}

PD-1 is an immunosuppressive cell-surface receptor expressed on immune cells, including activated $\mathrm{T}$ cells, regulatory $\mathrm{T}$ cells, B cells, natural killer cells, activated monocytes, and dendritic cells (14). PD-L1, one of the ligands of PD-1, is expressed on a wide range of malignancies, such as lung cancer (15), melanoma (16), and renal cell carcinoma (17), as well as on resting T cells, B cells, dendritic cells, macrophages, vascular endothelial cells, and pancreatic islet cells (14). For T cells to be activated, 2 signals are required. First, interaction between the antigen-major histocompatibility complex and the T-cell receptor on T cells needs to present. Second, a costimulatory signal provided by antigen-presenting cells (APCs) is needed. Once the T cells are activated, T-cell clonal expansion, cytokine secretion, and T-cell effector function are initiated. Binding of PD-1 to PD-L1 inhibits the costimulatory signal, leading to T-cell dysfunction and allowing tumor cells to evade the antitumor immune response (Fig. 1A).

\section{CTLA-4 Pathway}

Another key inhibitory immune checkpoint is CTLA-4. CD28, which is expressed on resting and activated T-cells, works as a costimulatory receptor and promotes T-cell proliferation and effector function on binding its ligand B7 on APCs. CTLA-4 is homologous to $\mathrm{CD} 28$ and shares the same B7 ligand but negatively effects $\mathrm{T}$-cell activation. Although resting $\mathrm{T}$ cells rarely express CTLA-4, CTLA-4 is upregulated after T-cell receptor 


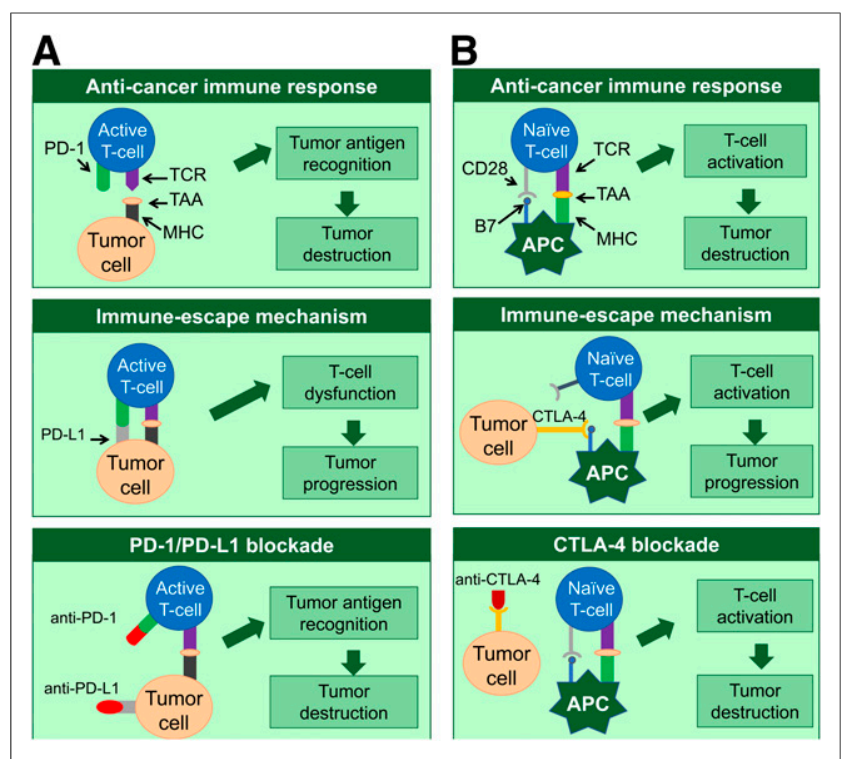

FIGURE 1. Simplified schematic representation of PD-1 (A) and CTLA4 (B) pathway and mechanism of blocking these pathways. TCR $=$ T-cell receptor; TAA = tumor-associated antigen; $\mathrm{MHC}=$ major histocompatibility complex.

(TCR) activation and binds B7 with a higher avidity than CD28, resulting in reduced $\mathrm{T}$-cell proliferation. In addition, regulatory $\mathrm{T}$ cells control functions of effector $\mathrm{T}$ cells and thus are key players in maintaining peripheral tolerance, as regulatory $\mathrm{T}$ cells constitutively express CTLA-4, which is thought to be important for their suppressive functions (3). Recently, CTLA-4 was found to be expressed on various malignant tissues (18-25), and it correlates with outcome in certain cases $(21,23,26)$. Upregulation of CTLA4 by tumor cells may prevent APCs from presenting tumor-associated antigens to naive $\mathrm{T}$ cells. Consequently, T-cell activation and tumor destruction can be prevented (Fig. 1B). Ipilimumab, an anti-CTLA-4 antibody, was approved by the Food and Drug Administration in 2011 for treatment of metastatic and high-risk resected melanoma and has been shown to be effective in multiple phase II and III trials (27).

\section{ROLE OF IMAGING OF IMMUNE CHECKPOINT BLOCKADE}

In the oncologic setting, imaging with CT, MRI, and PET/CT is applied for 3 main reasons: staging or patient selection, evaluation of treatment responses, and monitoring or follow-up after therapy. Because immune checkpoint blockade is an expensive treatment that can have severe side effects, careful patient selection is of great importance.

Although conventional imaging methods such as CT and MRI are limited mainly to anatomic and functional assessment of a patient's tumor load, PET provides us with the possibility of performing molecular functional imaging. Recent reports have highlighted the potential of ${ }^{18} \mathrm{~F}$-FDG PET/CT for the assessment of responses to immunotherapies $(28,29)$. However, its role in predicting responses before administration of the therapy to optimize patient selection remains to be determined. Also, some initial data suggest that the ${ }^{18} \mathrm{~F}$-FDG uptake before initiation of treatment with nivolumab or pembrolizumab may have some value in predicting the treatment outcome (30). Although, for immunotherapies, only limited data are available, this potential use of PET is well known in other treatments, such as chemotherapy or external-beam radiation. For example, PET features in the pretherapeutic PET/CT scan can predict the response to neoadjuvant treatment of rectal cancer (31). Similar results were found in, for example, esophageal cancer $(32,33)$ or neuroendocrine tumors using somatostatin receptor PET (34).

At present, patient selection is based mainly on immunohistochemical analysis of biopsy material. Unfortunately, this approach has several limitations. First, expression levels and the invasion of tumor-infiltrating lymphocytes changes over time because of alterations in the tumor microenvironment or in response to treatments (35-41). Second, expression levels can be very heterogeneous within and between tumor lesions. Therefore, even though biopsy specimens may express high levels of PD-L1 at a given time, most lesions in the patient may actually be negative for these markers, potentially leading to misinterpretation of the overall PD-L1 status if only a single biopsy specimen is analyzed (42-48).

To overcome these limitations, target-specific tracers for realtime in vivo imaging are currently under investigation and may have great potential to improve patient selection before immune checkpoint blockade therapy (Fig. 2).

\section{PRECLINICAL ADVANCES IN IMMUNE CHECKPOINT IMAGING}

\section{Imaging of PD-L1 Expression}

Currently, most checkpoint imaging studies have focused on visualizing PD-L1 expression, whether on tumor cells or in the tumor microenvironment. Among these studies, various targeting molecules have been evaluated, but antibody molecules have been most frequently used.

PD-L1 Imaging Based on Antibody Molecules. So far, a series of preclinical studies has shown feasibility to specifically visualize PD-L1 expression using radiolabeled anti-PD-L1 antibodies for PET or SPECT imaging (Tables 1 and 2). Specific tracer uptake with high tumor-to-background contrast was reported for various PD-L1-expressing xenografts, with low uptake in PD-L1-negative tumors (49-51). In addition, graded levels of PD-L1 expression were shown to be detectable in different human tumor xenografts (CHO-PDL1, MDA-MB-231, H2444) (50), and intratumoral heterogeneity could be visualized (52). One disadvantage of xenograft tumor models is that immunodeficient mice are needed. Consequently, expression of PD-L1 on healthy organs and immune cells cannot be evaluated. To overcome this problem, immunocompetent mice with murine tumors are increasingly being used, together with antimurine anti-PD-L1 antibodies as targeting molecules. Besides high uptake of the radiolabeled anti-PD-L1 antibodies in tumor tissue, tracer uptake in healthy PD-L1-expressing tissues such as brown fat, spleen, liver, thymus, heart, and lungs was reported (53).

Another important consideration is the impact of protein concentration on the distribution of radiolabeled anti-PD-L1 antibodies. Nedrow et al. observed an increasing tumor uptake with escalating tracer doses, which the authors hypothesized may be due to the spleen acting as a sink for the anti-PD-L1 antibody (54). To enhance uptake in tumors, a therapeutic dose of unlabeled anti-PD-L1 antibody was added to the tracer dose of ${ }^{111}$ In-DTPAanti-PD-L1 to block PD-L1 binding sites in the spleen. In this study, a $3 \mathrm{mg} / \mathrm{kg}$ dose of antibody led to optimal biodistribution and tumor-to-background ratios. The hypothesis that it is possible to monitor the impact of PD-L1-rich organs on the distribution of anti-PD-L1 antibodies was confirmed (54). 


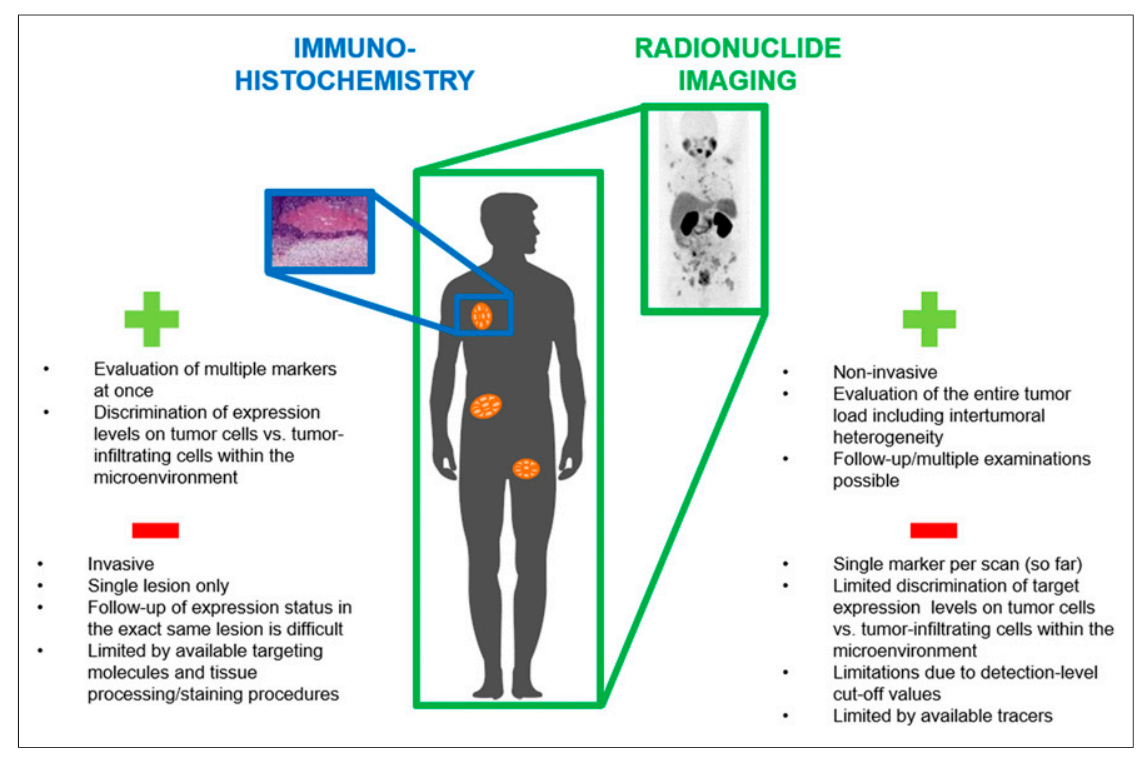

FIGURE 2. Schematic representation of advantages and limitations of immunohistochemical analysis of checkpoint expression levels vs. checkpoint imaging.

Other than ${ }^{111}$ In (SPECT), anti-PD-L1 antibodies have been labeled with radioisotopes such as ${ }^{64} \mathrm{Cu}$ or ${ }^{89} \mathrm{Zr}$ for PET imaging applications $(55,56)$. Lesniak et al. evaluated the anti-PD-L1 antibody atezolizumab labeled with ${ }^{64} \mathrm{Cu}$ using the chelator DOTAGA for PET imaging of PD-L1 expression, showing high tracer uptake in PD-L1-expressing tumors (57). Recently, a DOTAGA-chelated, ${ }^{111}$ In-labeled anti-HER3 Affibody (Affibody $\mathrm{AB}$ ) carrying a negative charge at the $\mathrm{C}$ terminus was shown to have significantly lower liver uptake than the ${ }^{111}$ In-labeled NOTAchelated variant (58). This observation has not yet been confirmed for anti-PD-L1 antibodies, but this possibility should be evaluated in order to optimize the biodistribution profile of these antibodies regarding sink effects of the liver.

Most of the above-described studies focused on developing approaches to visualize PD-L1 expression with SPECT or PET and on further optimizing these imaging approaches by varying the protein dose, the radioisotope, or the chelating molecule. In addition to pure a priori visualization of the checkpoint expression status in oncologic patients, knowledge of the impact of different therapies on the expression status would be desirable. Hettich et al. evaluated the effect of interferon- $\gamma$ treatment on PD-L1 expression (55). They found that PD-L1 expression in mice with wild-type B16F10 melanomas was augmented on interferon- $\gamma$ treatment and were able to visualize this. Kikuchi et al. provided evidence that radiotherapy induces changes in PD-L1 expression that could be visualized with PET/CT imaging (59). Radiotherapy was able to induce an upregulation of PD-L1 on B16F10 melanoma cells. This upregulation may affect the response to PD-L1-based checkpoint blockade therapy but is a dynamic process that has been difficult to monitor during treatment in the clinical situation. In this particular study, PET/CT performed at 48 or $96 \mathrm{~h}$ after injection was suitable for confirming PD-L1 increases in irradiated tumors before the commencement of immune checkpoint therapy or other interventions. Feasibility for visualizing radiotherapy-induced changes in PD-L1 expression was confirmed by other groups using SPECT with ${ }^{111}$ In-labeled anti-PD-L1 antibodies (52) or PET using ${ }^{89} \mathrm{Zr}$-labeled tracers $(60)$. In the latter study, increases in PD-L1 expression from baseline were observed in H460 cells after daily radiotherapy of 5 fractions of 2 Gy and could be visualized in vivo with ${ }^{89} \mathrm{Zr}$-Df-atezolizumab PET imaging. Interestingly, a statistically significant higher tracer accumulation was reported in fractionated $\mathrm{H} 460$ tumors than in any other H460 group.

PD-L1 Imaging Based on Smaller Targeting Molecules. One limitation of the described studies on checkpoint imaging is the fact that full-length $\mathrm{IgG}$ antibodies were used $(\sim 150 \mathrm{kDa})$, which, because of their size, may have limited tissue and tumor penetrance. Therefore, the interval between tracer injection and imaging needs to be long enough and corresponding radioisotopes such as ${ }^{111} \mathrm{In}$ or ${ }^{64} \mathrm{Cu}$ need to be used, resulting in an increased radiation dose and more complex clinical protocols.

To improve this situation for PD-L1 imaging, $\mathrm{Li}$ et al. evaluated an $80-\mathrm{kDa}$ antihuman PD-L1 domain antibody containing an Fc tail fused to 2 single domains and labeled with ${ }^{89} \mathrm{Zr}$ via deferoxamine (61), hoping to improve tumor penetration and tumor-to-background ratios at earlier time points than monoclonal antibodies. Indeed, high tumor-to-background contrast was observed at $24 \mathrm{~h}$ after injection.

Other approaches toward fast target accumulation and rapid clearance of unbound tracer include the use of even smaller targeting molecules such as the Fab fragments ${ }^{64} \mathrm{Cu}$-NOTA-antiPD-L1-Fab (62), which retain the binding of antibodies but lack the Fc effector domain, leading to altered pharmacokinetics, including shorter circulation half-lives. Besides Fab fragments ( $\sim 55$ $\mathrm{kDa}$, checkpoint imaging using small molecules, including ${ }^{99} \mathrm{~m}$ Tc- and ${ }^{68} \mathrm{Ga}$-labeled single-domain antibodies $(\sim 15 \mathrm{kDa})$, ${ }^{18}$ F-labeled adnectins $(\sim 10 \mathrm{kDa}),{ }^{18} \mathrm{~F}-\mathrm{AlF}-$ labeled Affibody molecules $(\sim 6 \mathrm{kDa})$, and peptides $(<1 \mathrm{kDa})$, has been investigated (63-69). Because of the small size of these targeting molecules as compared with antibody molecules, these agents are delivered rapidly to their targets, with fast clearance of the unbound probe, providing high image-contrast. In addition, some of these targeting molecules, such as adnectins, are very stable and the absence of cysteine or disulfide bonds allows the introduction of a single cysteine for site-specific conjugation of radioisotopes. In vivo imaging indeed revealed rapid delivery of these tracers to PD-L1expressing tumors and rapid clearance from tumors and tissues that do not express PD-L1. Compared with intact antibody molecules, which are cleared not renally but via the hepatic route, smaller targeting molecules (depending on their size) are often cleared via the kidneys - a factor that should be considered when tumor lesions near these organs need to be evaluated.

The anti-PD-L1 peptide WL12 labeled with ${ }^{64} \mathrm{Cu}$ or ${ }^{68} \mathrm{Ga}$ was shown to detect tumor PD-L1 expression specifically and rapidly after injection of the radiotracer-a finding that fits within the standard clinical workflow of imaging within $60 \mathrm{~min}$ of administration $(67,68)$. Subsequently, the preparation of a radiofluorinated analog of WL12 using 2,3,5,6-tetrafluorophenyl-6- ${ }^{18}$ F-fluoronicotinate was reported (69). ${ }^{18} \mathrm{~F}$ is well suited to clinical translation, with $97 \%$ decay via positron emission and a half-life of $109.8 \mathrm{~min}$, allowing transportation of the radiotracer from the regional 
TABLE 1

Overview of Currently Available Preclinical Checkpoint Imaging Studies (for PD-L1)

\begin{tabular}{|c|c|c|c|c|c|c|}
\hline Targeting molecule & Radioisotope & Chelator & Animal model & Tumor model & $\begin{array}{l}\text { Accumulation } \\
\text { time }\end{array}$ & Study \\
\hline \multicolumn{7}{|l|}{ PD-L1 } \\
\hline Murine mAb PD-L1.3.1 & ${ }^{111}$ In & DTPA & BALB/c nude mice & $\begin{array}{l}\text { MDA-MB-231, } \\
\text { SK-Br-3, SUM149, } \\
\text { MCF-7, BT474 }\end{array}$ & $0,1,3,7 \mathrm{~d}$ & (49) \\
\hline Atezolizumab & ${ }^{111}$ In & DTPA & NSG mice & $\begin{array}{l}\text { CHO-PDL1, CHO, } \\
\text { H2444, H1155, } \\
\text { MDA-MB-231, } \\
\text { SUM149 }\end{array}$ & $\begin{array}{l}24,48,72 \\
\quad 96,120 \mathrm{~h}\end{array}$ & $(67)$ \\
\hline $\begin{array}{l}\text { Murine anti-PD-L1 } \\
\text { antibody }\end{array}$ & ${ }^{111}$ In & DTPA & $\begin{array}{l}\text { Neu-N transgenic } \\
\text { mice }\end{array}$ & NT2.5 & $72 \mathrm{~h}$ & (53) \\
\hline $\begin{array}{l}\text { Antimouse PD-L1 } \\
\text { antibody }\end{array}$ & ${ }^{111}$ In & DTPA & C57BL/6 mice & B16F10 & $24,72 \mathrm{~h}$ & (54) \\
\hline $\begin{array}{l}\text { Antimurine anti-PD-L1 } \\
\text { antibody a-PD-L1 } \\
\text { (10F.9G2) }\end{array}$ & ${ }^{64} \mathrm{Cu}$ & NOTA & C57BL/6N mice & B16F10 & $24 \mathrm{~h}$ & (55) \\
\hline $\begin{array}{l}\text { Anti-PD-L1 } \\
\text { antibody C4 }\end{array}$ & ${ }^{89} \mathrm{Zr}$ & DFO & $\begin{array}{l}\text { nu/nu mice, } \mathrm{C} 57 \\
\text { BL/6J mice }\end{array}$ & $\begin{array}{l}\mathrm{H} 1975, \mathrm{PC} 3 \\
\quad \text { A549 }\end{array}$ & $\begin{array}{l}8,24,48,72 \\
\text { and } 120 \mathrm{~h}\end{array}$ & (51) \\
\hline Atezolizumab & ${ }^{64} \mathrm{Cu}$ & DOTAGA & NSG mice & $\begin{array}{l}\text { CHO-hPD-L1, } \\
\text { MDA-MB-231, } \\
\text { CHO, SUM149 }\end{array}$ & $24,48 \mathrm{~h}$ & $(57)$ \\
\hline Avelumab & $89 \mathrm{Zr}$ & DFO & Athymic nude mice & MDA-MB-231 & $1,2,3,6 \mathrm{~d}$ & (56) \\
\hline $\begin{array}{l}\text { Antimurine anti-PD-L1 } \\
\text { antibody 10F.9G2 }\end{array}$ & ${ }^{89} \mathrm{Zr}$ & DFO & C57BL/6 mice & MEER, B16F10 & $48 h+96 h$ & (59) \\
\hline $\begin{array}{l}\text { AntihPD-L1, clone } \\
\text { PD-L1.3.1, antimPD-L1, } \\
\text { clone 10F.9G2 }\end{array}$ & ${ }^{111}$ In & DTPA & $\begin{array}{l}\text { BALB/c, } \\
\text { C57BL/6, } \\
\text { and NSG mice }\end{array}$ & $\begin{array}{l}\text { Renca, 4T1, CT26, } \\
\text { B16F1, LLC1 }\end{array}$ & $1,3,7 \mathrm{~d}$ & (52) \\
\hline Atezolizumab & ${ }^{89} \mathrm{Zr}$ & Df & Athymic nude mice & $\mathrm{H} 460, \mathrm{~A} 549$ & $\begin{array}{l}1,6,12,24 \\
48,72,96 \mathrm{~h}\end{array}$ & $(60)$ \\
\hline ZPD L1_1 Affibody & ${ }^{18} \mathrm{~F}-\mathrm{AlF}$ & NOTA & SCID beige mice & LOX, SUDHL6 & 30-90 min & (65) \\
\hline $\begin{array}{l}\text { KN035 domain antibody } \\
\text { containing Fc tail fused } \\
\text { to } 2 \text { single domains } \\
\text { (antihuman PD-L1) }\end{array}$ & ${ }^{89} \mathrm{Zr}$ & DFO & $\begin{array}{l}\text { BALB/c nude mice, } \\
\text { nonhuman primates }\end{array}$ & LN229 & $\begin{array}{r}1,6,24,48 \\
72,120 \mathrm{~h}\end{array}$ & (61) \\
\hline $\begin{array}{l}\text { PD-L1 specific Fab } \\
\text { fragment }\end{array}$ & ${ }^{64} \mathrm{Cu}$ & NOTA & Athymic nude mice & - & $5,15,45 \mathrm{~min}$ & (62) \\
\hline $\begin{array}{l}\text { Anti-PD-L1 adnectin } \\
\text { BMS-986192 }\end{array}$ & ${ }^{18} \mathrm{~F}$ & & Athymic nude mice & HT-29, L2987 & $90-120 \mathrm{~min}$ & (66) \\
\hline Peptide WL12 & ${ }^{64} \mathrm{Cu}$ & DOTAGA & NSG mice & $\mathrm{CHO}, \mathrm{hPD}-\mathrm{L} 1$ & $\begin{array}{r}10,30,60 \\
120 \mathrm{~min}\end{array}$ & (50) \\
\hline Peptide WL12 & ${ }^{68} \mathrm{Ga}$ & DOTAGA & NSG mice & $\begin{array}{l}\text { hPD-L1, CHO, } \\
\text { MDA-MB-231, } \\
\text { SUM149 }\end{array}$ & $\begin{array}{l}15,60 \\
120 \min \end{array}$ & (68) \\
\hline Peptide WL12 & ${ }^{18} \mathrm{~F}$ & & NSG mice & $\begin{array}{l}\text { hPD-L1, CHO, } \\
\text { H226, H1155, } \\
\text { MDA-MB-231, } \\
\text { SUM149 }\end{array}$ & $10,60,120 \mathrm{~min}$ & (69) \\
\hline $\begin{array}{l}\text { Single-domain } \\
\text { antibodies C3, C7, } \\
\text { E2 and E4 }\end{array}$ & 99mTc & & C57BL/6 mice & HEK293T & $1 \mathrm{~h}$ & (63) \\
\hline $\begin{array}{l}\text { Single-domain antibody } \\
\text { Nb109 }\end{array}$ & ${ }^{68} \mathrm{Ga}$ & NOTA & BALB/c nude mice & $\begin{array}{l}\text { A375-hPD-L1, } \\
\text { MCF-7 }\end{array}$ & $1,2,4 \mathrm{~h}$ & (64) \\
\hline $\mathrm{O}=$ deferoxamine. & & & & & & \\
\hline
\end{tabular}

1140 The Journal of Nuclear Medicine • Vol. 61 • No. 8 • August 2020 
TABLE 2

Overview of Currently Available Preclinical Checkpoint Imaging Studies (for PD-1, CTLA-4, and LAG-3)

\begin{tabular}{|c|c|c|c|c|c|c|}
\hline Targeting molecule & Radioisotope & Chelator & Animal model & Tumor model & $\begin{array}{l}\text { Accumulation } \\
\text { time }\end{array}$ & Study \\
\hline \multicolumn{7}{|l|}{ PD-1 } \\
\hline Anti-PD-1 antibody & ${ }^{64} \mathrm{Cu}$ & DOTA & Foxp3+ LuciDTR4 mice & B16F10 & $48 \mathrm{~h}$ & $(71)$ \\
\hline Anti-PD-1 antibody & ${ }^{64} \mathrm{Cu}$ & NOTA & C57BL/6 mice & B16F10 & $24 \mathrm{~h}$ & (55) \\
\hline Nivolumab & $89 \mathrm{Zr}$ & DFO & $\begin{array}{l}\text { Cynomolgus } \\
\text { nonhuman primates }\end{array}$ & - & $1,4,6,8 d$ & (72) \\
\hline Nivolumab & ${ }^{89} \mathrm{Zr}$ & Df & NSG mice & A549 & $\begin{array}{c}3,6,12,24,48 \\
72,168 \mathrm{~h}\end{array}$ & (73) \\
\hline Pembrolizumab & ${ }^{89} \mathrm{Zr}$ & Df & $\begin{array}{l}\text { ICR (CD-1), SCID, and } \\
\text { NSG mice and Sprague- } \\
\text { Dawley outbred rats }\end{array}$ & - & $\begin{array}{l}0.5,6,12,24 \\
\quad 48,72,120 \\
168 \mathrm{~h}\end{array}$ & (74) \\
\hline Pembrolizumab & ${ }^{89} \mathrm{Zr},{ }^{64} \mathrm{Cu}$ & DOTA & NSG mice & A375 & $\begin{array}{l}1,4,18,24,48 \\
72,96,120 \\
144 \mathrm{~h}\end{array}$ & (75) \\
\hline \multicolumn{7}{|l|}{ CTLA-4 } \\
\hline Ipilimumab & ${ }^{64} \mathrm{Cu}$ & DOTA & Athymic nude mice & A549, H358 & $48 \mathrm{~h}$ & (22) \\
\hline $\begin{array}{l}\text { Ipilimumab and } F\left(a b^{\prime}\right)_{2} \\
\text { fragment of ipilimumab }\end{array}$ & ${ }^{64} \mathrm{Cu}$ & NOTA & $\begin{array}{l}\text { Humanized NBSGW } \\
\text { mice }\end{array}$ & - & $\begin{array}{r}0.5,3,12 \\
24,48 \mathrm{~h}\end{array}$ & $(77)$ \\
\hline $\begin{array}{l}\text { LAG-3 (fully human } \\
\text { antibody REGN3767) }\end{array}$ & ${ }^{89} \mathrm{Zr}$ & DFO & $\begin{array}{l}\text { Immunodeficient } \\
\text { mice }\end{array}$ & MC38 & $6 \mathrm{~d}$ & (78) \\
\hline
\end{tabular}

radiopharmacy to the clinical site. In vivo data demonstrated a PD-L1-specific uptake of ${ }^{18} \mathrm{~F}-\mathrm{FPy}-\mathrm{WL} 12$ in a series of tumors on NSG mice (The Jackson Laboratory). In addition to PD-L1expressing tumors, high accumulation of the tracer was observed in liver and kidneys and could not be blocked, suggesting a nonspecific accumulation of the radiotracer in these organs.

Taken together, these data show that several alternatives to intact IgG molecules are available and are currently being tested for checkpoint imaging purposes. So far, the first results look promising, and the fact that even tracers for PET have become available will stimulate further research toward clinical translation. These tracer alternatives are particularly interesting in view of their small size and fast clearance profiles, which imply that imaging can be performed as early as minutes to hours after injection. Together with the advantages in practical workflows in the clinical situation, using smaller targeting agents also limits the amount of time patients are exposed to radioactivity.

\section{Imaging of PD-1 Expression}

Previously, a correlation between response to PD-1 checkpoint blockade and the presence of PD-1-expressing tumor-infiltrating lymphocytes has been shown $(45,70)$. So far, several studies have focused on the development of PD-1-specific imaging approaches to visualize PD-1-expressing T cells in the tumor microenvironment and in immune tissues. Although several targeting molecules (including antibodies, antibody fragments, and small molecules) have been tested for PD-L1 imaging so far, PD-1 imaging was performed almost exclusively with IgG molecules, including ${ }^{64} \mathrm{Cu}$-DOTA-antiPD-1 (71), ${ }^{64} \mathrm{Cu}$-NOTA-anti-PD-1 (55), ${ }^{89} \mathrm{Zr}$-deferoxamine-nivolumab (72), ${ }^{89} \mathrm{Zr}$-Df-nivolumab (73), and ${ }^{89} \mathrm{Zr}$-Df-pembrolizumab $(74,75)$. Besides visualization of PD-1-expressing tumor-infiltrating lymphocytes in the tumor microenvironment, specific uptake was observed in the spleen and lymph nodes, as is due to PD-1 expression in lymphocytes. In addition, salivary and lacrimal gland infiltration of $\mathrm{T}$ cells was reported (73). Taken together, these findings support the idea that PD-1-specific PET imaging may contribute to patient selection because it may have potential to aid in predicting response to therapies targeting immune checkpoints and become a tool for disease monitoring.

\section{Imaging of CTLA-4 Expression}

One of the first immune checkpoints that has been targeted for checkpoint blockade therapy is CTLA-4 (76). Ehlerding et al. investigated the potential of CTLA-4 as a target for PET imaging and were able to visualize CTLA-4 expression on NSCLC with ${ }^{64} \mathrm{Cu}$-DOTA-ipilimumab PET/CT (22) and ${ }^{64} \mathrm{Cu}-\mathrm{NOTA}$-ipilimumab PET/CT in humanized mouse models (77). In addition, a ${ }^{64} \mathrm{Cu}-$ labeled $\mathrm{F}\left(\mathrm{ab}^{\prime}\right)_{2}$ fragment of ipilimumab was assessed for PET imaging of CTLA-4 expression on T cells. ${ }^{64} \mathrm{Cu}$-NOTA-ipilimumab demonstrated high absolute uptake in the salivary glands of the humanized mice, a finding that the authors attributed to graft-versushost disease. In contrast, ${ }^{64} \mathrm{Cu}-\mathrm{NOTA}$-ipilimumab-F $\left(\mathrm{ab}^{\prime}\right)_{2}$ uptake was lower. However, rapid clearance from the circulation was observed for the $\mathrm{F}\left(\mathrm{ab}^{\prime}\right)_{2}$ agent, leading to higher salivary gland-to-blood ratios.

In summary, whether one uses IgGs or smaller fragments as targeting molecules, visualization of CTLA-4 expression seems feasible.

\section{OTHER IMAGING TARGETS}

Kelly et al. assessed the fully human antibody REGN3767 radiolabeled with ${ }^{89} \mathrm{Zr}$ using the bifunctional chelator deferoxamine, which is directed against the lymphocyte-activation gene 3 (LAG-3) (78). LAG-3 is an immune checkpoint target expressed by activated T lymphocytes, which reduce T-cell function (79). Lag-3-expressing tumor-infiltrating lymphocytes correlate with a large mass volume 
of malignancies, high proliferation rates, and poor prognosis. In vivo, ${ }^{89} \mathrm{Zr}$-REGN3767 showed high specific uptake in human LAG-3-expressing M38 tumors in immunodeficient mice. In addition, LAG-3-positive $\mathrm{T}$ cells in the spleen could be detected. Overall, these findings support the idea of LAG-3-based PET for the assessment of LAG-3 expression, with the goal of predicting and monitoring response to checkpoint blockade in the future.

\section{CURRENT CLINICAL STATUS}

Although the above-described studies evaluated these novel checkpoint imaging approaches in animal models, the first results on checkpoint-specific PET imaging in humans were recently published.

Niemeijer et al. reported the first-in-humans study of wholebody PET imaging with ${ }^{89} \mathrm{Zr}$-nivolumab (anti-PD-1) (7 d after injection) and ${ }^{18} \mathrm{~F}-\mathrm{BMS}-986192$, an ${ }^{18} \mathrm{~F}$-labeled anti-PD-L1 adnectin ( $1 \mathrm{~h}$ after injection), in 13 patients with advanced NSCLC, before treatment with nivolumab (80). Both tracers showed adequate tumorto-background contrast for tumor visualization. However, between patients, as well as between different tumor lesions, heterogeneous uptake was reported for both tracers. ${ }^{18} \mathrm{~F}-\mathrm{BMS}-986192$ uptake in tumor lesions correlated with tumor PD-L1 expression as measured by immunohistochemistry. ${ }^{89} \mathrm{Zr}$-nivolumab uptake correlated with PD-1-expressing tumor-infiltrating immune cells. Both tracers showed a high accumulation in the spleen, which the authors attributed to binding to PD-1 and PD-L1 receptors on lymphocytes and dendritic cells. Moreover, tracer uptake in the liver was observed, likely due to catabolism of the tracers. The smaller ${ }^{18} \mathrm{~F}-\mathrm{BMS}-$ 986192 tracer demonstrated mainly biliary and renal excretion, whereas ${ }^{89} \mathrm{Zr}$-nivolumab was excreted via the gastrointestinal route, as is typical for monoclonal antibodies. Overall, for both tracers, the authors reported a correlation between tracer uptake in the tumors and response to nivolumab treatment. In summary, these findings suggest that PD-1- and PD-L1-specific PET/CT imaging may be useful for noninvasively evaluating PD-1 and PD-L1 expression in patients with NSCLC.

Bensch at al. recently presented the initial results of a first-inhumans study evaluating the ${ }^{89} \mathrm{Zr}$-labeled anti-PD-L1 antibody atezolizumab in 22 patients with locally advanced or metastatic bladder cancer, NSCLC, or triple-negative breast cancer before the start of atezolizumab therapy with PET/CT (81). The authors were able to show that the imaging signal corresponds to PD-L1 expression at sites of inflammation and in various normal lymphoid tissues. In tumors, high but heterogeneous uptake was observed, varying within and among lesions, patients, and tumor types (Fig. 3). Interestingly, for progression-free and overall survival, the tracer uptake appeared to be a strong predictor of response to atezolizumab treatment.

In yet another first-in-humans study, Xing et al. assessed the single-domain anti-PD-L1 antibody NM-01, which was sitespecifically labeled with ${ }^{99 \mathrm{~m}} \mathrm{Tc}$ for SPECT imaging in 16 patients with NSCLC (82). The administered activity ranged from 3.8 to $10.4 \mathrm{MBq} / \mathrm{kg}$ of body weight, corresponding to 100 or $400 \mu \mathrm{g}$ of NM-01. Tracer uptake was observed in kidneys, spleen, liver, and bone marrow, with an acceptable radiation dosimetry profile. The different protein doses revealed no significant difference in tumorto-background ratios. The authors concluded that ${ }^{99 \mathrm{~m}} \mathrm{Tc}-\mathrm{NM}-01-$ based SPECT is a safe diagnostic procedure delivering a tolerable radiation dose and has favorable biodistribution and image characteristics correlating with PD-L1 immunohistochemical staining in patients with NSCLC.

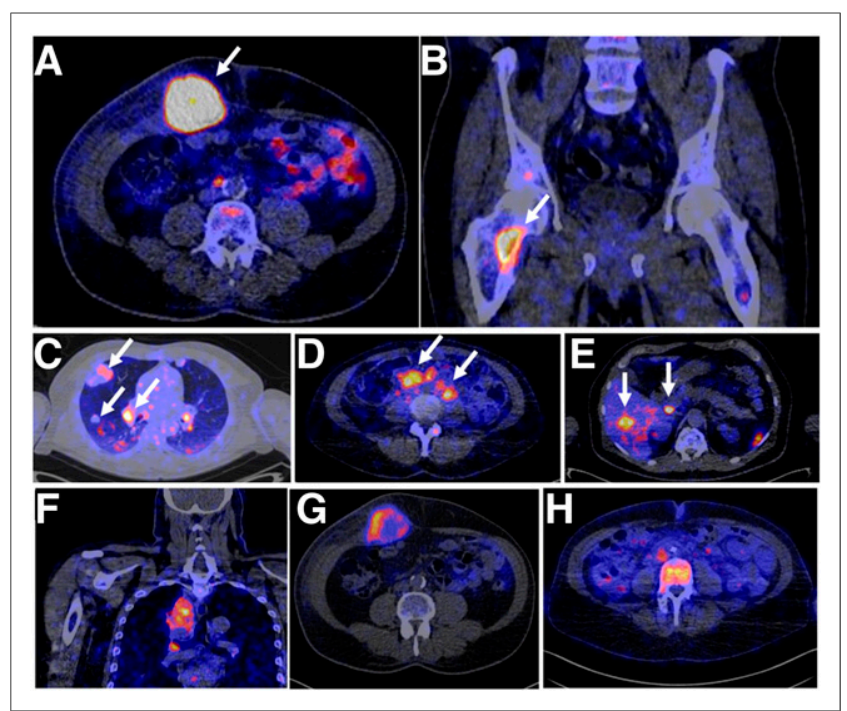

FIGURE 3. (A-E) PET/CT images of 4 patients illustrating ${ }^{89} \mathrm{Zr}$-atezolizumab tumor uptake in 5 different locations on day 7 after injection (arrows indicate tumors). (F-G) PET/CT images of lesions of 3 patients with heterogeneous intralesional ${ }^{89} \mathrm{Zr}$-atezolizumab uptake on day 7 after injection: mediastinal lesion of NSCLC patient $\left(\mathrm{SUV}_{\max }, 19.9\right)(\mathrm{F})$, abdominal wall metastases of bladder cancer patient $\left(\mathrm{SUV}_{\max }, 36.4\right)(\mathrm{G})$, and bone metastasis of breast cancer patient $\left(\mathrm{SUV}_{\max }, 7.1\right)(\mathrm{H})$. (Adapted with permission of (81).)

\section{SUMMARY AND OUTLOOK}

We have provided an overview on recent developments in checkpoint imaging in oncology. So far, the first evidence for noninvasive visualization of various targets for immune checkpoint blockade therapy has been provided using radiolabeled antibodies, antibody fragments, single-domain antibodies, peptides, and adnectins for SPECT and PET imaging. Besides pure a priori visualization of target expression levels in the tumor tissue, analysis of expression heterogeneity within and between tumor lesions has been reported. In addition, evidence for visualizing the infiltration of targetexpressing $\mathrm{T}$ cells into the tumor microenvironment and in healthy immune tissues has been provided, and checkpoint imaging has been reported to allow monitoring of changes in target expression levels on application of different treatments (radiotherapy, interferon- $\gamma$ ). Finally, first evidence suggests that checkpoint imaging may be used to predict responses to checkpoint blockade therapy.

The first clinical studies have been performed, focusing mainly on visualization of PD-L1, and have shown encouraging results. Numerous other clinical studies have been initiated, with their results yet to come. However, prior to full clinical exploitation of checkpoint imaging, various aspects still have to be investigated. Among the variety of different targeting molecules being evaluated, consensus should be reached on which tracers are most suitable to meet clinical needs. Studies are needed to directly compare smaller targeting molecules with intact IgG molecules for checkpoint imaging and to select which radioisotopes and chelating molecules optimally match the pharmacokinetics of these targeting molecules. In addition, further studies should address in which situations imaging of the checkpoint receptor should be performed and in which situations the ligand should be targeted. Moreover, the impact of false-positive situations, such as in infections, which frequently are accompanied by an influx of immune cells, should be evaluated. 
Since visualization of immune cell infiltration seems to be possible, applications of checkpoint imaging may not be limited to oncologic scenarios but might also be applied in infectious or inflammatory situations and autoimmune conditions.

Although checkpoint imaging is still in the early stages of development and many facets must be worked out before full clinical exploitation, the results obtained so far look promising. Eventually, checkpoint imaging may help to optimize patient selection, predict and monitor responses to checkpoint blockade, and aid the development of novel combinatorial, personalized regimens that suit each patient's individual situation.

\section{DISCLOSURE}

This study was funded by the Deutsche Forschungsgemeinschaft (DFG, German Research Foundation) under Germany's Excellence Strategy - EXC2151 - 390873048. No other potential conflict of interest relevant to this article was reported.

\section{KEY POINTS}

QUESTION: What is the role of immune checkpoint imaging in oncology with respect to personalized patient care?

PERTINENT FINDINGS: This review article provides an overview on the current developments in immune checkpoint imaging. Various preclinical studies have shown proof of principle for visualizing target expression levels in the tumor tissue and infiltration of target-expressing immune cells into the tumor microenvironment. Checkpoint imaging has been shown to be feasible for monitoring expression-level changes upon treatment and may be used to predict responses to checkpoint blockade therapy. On the basis of these promising findings, numerous clinical studies have been initiated.

IMPLICATIONS FOR PATIENT CARE: Immune checkpoint imaging may drastically improve patient selection and response evaluation in oncologic patients before, during, and after treatment with checkpoint inhibitors.

\section{REFERENCES}

1. Hanahan D, Weinberg RA. Hallmarks of cancer: the next generation. Cell. 2011; 144:646-674.

2. Topalian SL, Hodi FS, Brahmer JR, et al. Safety, activity, and immune correlates of anti-PD-1 antibody in cancer. N Engl J Med. 2012;366:2443-2454.

3. Buchbinder EI, Desai A. CTLA-4 and PD-1 pathways: similarities, differences, and implications of their inhibition. Am J Clin Oncol. 2016;39:98-106.

4. Hodi FS, Chiarion-Sileni V, Gonzalez R, et al. Nivolumab plus ipilimumab or nivolumab alone versus ipilimumab alone in advanced melanoma (CheckMate 067): 4-year outcomes of a multicentre, randomised, phase 3 trial. Lancet Oncol. 2018;19:1480-1492.

5. Paz-Ares L, Brahmer J, Hellmann MD, et al. CheckMate 227: a randomized, open-label phase 3 trial of nivolumab, nivolumab plus ipilimumab, or nivolumab plus chemotherapy versus chemotherapy in chemotherapy-naive patients with advanced non-small cell lung cancer (NSCLC) [abstract]. Ann Oncol. 2017; 28(suppl 2):50-51

6. Mok TSK, Wu YL, Kudaba I, et al. Pembrolizumab versus chemotherapy for previously untreated, PD-L1-expressing, locally advanced or metastatic non-small-cell lung cancer (KEYNOTE-042): a randomised, open-label, controlled, phase 3 trial. Lancet. 2019;393:1819-1830.

7. Mezquita L, Planchard D. Durvalumab for the treatment of non-small cell lung cancer. Expert Rev Respir Med. 2018;12:627-639.

8. Barlesi F, Vansteenkiste J, Spigel D. Avelumab versus docetaxel in patients with platinum-treated advanced non-small-cell lung cancer (JAVELIN Lung 200): an open-label, randomised, phase 3 study. Lancet Oncol. 2018;19:1468-1479.
9. Rini BI, Powles T, Atkins MB, et al. Atezolizumab plus bevacizumab versus sunitinib in patients with previously untreated metastatic renal cell carcinoma (IMmotion151): a multicentre, open-label, phase 3, randomised controlled trial. Lancet. 2019;393:2404-2415.

10. Reck M, Rodriguez-Abreu D, Robinson AG, et al. Pembrolizumab versus chemotherapy for PD-L1-positive non-small-cell lung cancer. N Engl J Med. 2016; 375:1823-1833.

11. Naidoo J, Page DB, Li BT, et al. Toxicities of the anti-PD-1 and anti-PD-L1 immune checkpoint antibodies. Ann Oncol. 2015;26:2375-2391.

12. Freeman-Keller M, Kim Y, Cronin H, Richards A, Gibney G, Weber JS. Nivolumab in resected and unresectable metastatic melanoma: characteristics of immune-related adverse events and association with outcomes. Clin Cancer Res. 2016;22:886-894

13. Kazandjian D, Khozin S, Blumenthal G, et al. Benefit-risk summary of nivolumab for patients with metastatic squamous cell lung cancer after platinum-based chemotherapy: a report from the US Food and Drug Administration. JAMA Oncol. 2016;2:118-122.

14. Keir ME, Butte MJ, Freeman GJ, Sharpe AH. PD-1 and its ligands in tolerance and immunity. Annu Rev Immunol. 2008;26:677-704.

15. He J, Hu Y, Hu M, Li B. Development of PD-1/PD-L1 pathway in tumor immune microenvironment and treatment for non-small cell lung cancer. Sci Rep. 2015; 5:13110.

16. Taube JM, Young GD, McMiller TL, et al. Differential expression of immuneregulatory genes associated with PD-L1 display in melanoma: implications for PD-1 pathway blockade. Clin Cancer Res. 2015;21:3969-3976.

17. Motzer RJ, Escudier B, McDermott DF, et al. Nivolumab versus everolimus in advanced renal-cell carcinoma. N Engl J Med. 2015;373:1803-1813.

18. Weber JS. Tumor evasion may occur via expression of regulatory molecules: a case for CTLA-4 in melanoma. J Invest Dermatol. 2008;128:2750-2752.

19. Shah KV, Chien AJ, Yee C, Moon RT. CTLA-4 is a direct target of Wnt/betacatenin signaling and is expressed in human melanoma tumors. J Invest Dermatol. 2008;128:2870-2879.

20. Contardi E, Palmisano GL, Tazzari PL, et al. CTLA-4 is constitutively expressed on tumor cells and can trigger apoptosis upon ligand interaction. Int J Cancer. 2005; 117:538-550.

21. Salvi S, Fontana V, Boccardo S, et al. Evaluation of CTLA-4 expression and relevance as a novel prognostic factor in patients with non-small cell lung cancer. Cancer Immunol Immunother. 2012;61:1463-1472.

22. Ehlerding EB, England CG, Majewski RL, et al. ImmunoPET imaging of CTLA4 expression in mouse models of non-small cell lung cancer. Mol Pharm. 2017; 14:1782-1789.

23. Antczak A, Pastuszak-Lewandoska D, Gorski P, et al. Ctla-4 expression and polymorphisms in lung tissue of patients with diagnosed non-small-cell lung cancer. BioMed Res Int. 2013;2013:576486.

24. Buchbinder E, Hodi FS. Cytotoxic T lymphocyte antigen-4 and immune checkpoint blockade. J Clin Invest. 2015;125:3377-3383.

25. Callahan MK, Wolchok JD. At the bedside: CTLA-4- and PD-1-blocking antibodies in cancer immunotherapy. J Leukoc Biol. 2013;94:41-53.

26. Kassardjian A, Shintaku PI, Moatamed NA. Expression of immune checkpoint regulators, cytotoxic T lymphocyte antigen 4 (CTLA-4) and programmed deathligand 1 (PD-L1), in female breast carcinomas. PLoS One. 2018;13:e195958.

27. Hodi FS, O'Day SJ, McDermott DF, et al. Improved survival with ipilimumab in patients with metastatic melanoma. $N$ Engl J Med. 2010;363:711-723.

28. Wong ANM, McArthur GA, Hofman MS, Hicks RJ. The advantages and challenges of using FDG PET/CT for response assessment in melanoma in the era of targeted agents and immunotherapy. Eur J Nucl Med Mol Imaging. 2017;44:6777.

29. Cho SY, Lipson EJ, Im HJ, et al. Prediction of response to immune checkpoint inhibitor therapy using early-time-point ${ }^{18} \mathrm{~F}$-FDG PET/CT imaging in patients with advanced melanoma. $J$ Nucl Med. 2017;58:1421-1428.

30. Takada K, Toyokawa G, Yoneshima Y, et al. ${ }^{18} \mathrm{~F}-\mathrm{FDG}$ uptake in PET/CT is a potential predictive biomarker of response to anti-PD-1 antibody therapy in nonsmall cell lung cancer. Sci Rep. 2019;9:13362.

31. Bundschuh RA, Dinges J, Neumann L, et al. Textural parameters of tumor heterogeneity in ${ }^{18} \mathrm{~F}$-FDG PET/CT for therapy response assessment and prognosis in patients with locally advanced rectal cancer. J Nucl Med. 2014;55:891-897.

32. Levine EA, Farmer MR, Clark P, et al. Predictive value of 18-fluoro-deoxyglucose-positron emission tomography $\left({ }^{18} \mathrm{~F}-\mathrm{FDG}-\mathrm{PET}\right)$ in the identification of responders to chemoradiation therapy for the treatment of locally advanced esophageal cancer. Ann Surg. 2006;243:472-478.

33. Rizk NP, Tang L, Adusumilli PS, et al. Predictive value of initial PET-SUVmax in patients with locally advanced esophageal and gastroesophageal junction adenocarcinoma. J Thorac Oncol. 2009;4:875-879. 
34. Werner RA, Ilhan H, Lehner S, et al. Pre-therapy somatostatin receptor-based heterogeneity predicts overall survival in pancreatic neuroendocrine tumor patients undergoing peptide receptor radionuclide therapy. Mol Imaging Biol. 2018; 20:1068.

35. Dong H, Strome SE, Salomao DR, et al. Tumor-associated B7-H1 promotes T-cell apoptosis: a potential mechanism of immune evasion. Nat Med. 2002;8:793-800.

36. Joseph RW, Parasramka M, Eckel-Passow JE, et al. Inverse association between programmed death ligand 1 and genes in the VEGF pathway in primary clear cell renal cell carcinoma. Cancer Immunol Res. 2013;1:378-385.

37. Kondo A, Yamashita $\mathrm{T}$, Tamura $\mathrm{H}$, et al. Interferon-gamma and tumor necrosis factor-alpha induce an immunoinhibitory molecule, B7-H1, via nuclear factorkappaB activation in blasts in myelodysplastic syndromes. Blood. 2010;116: 1124-1131.

38. Ghebeh H, Lehe C, Barhoush E, et al. Doxorubicin downregulates cell surface B7-H1 expression and upregulates its nuclear expression in breast cancer cells: role of B7-H1 as an anti-apoptotic molecule. Breast Cancer Res. 2010;12:R48.

39. Zhang P, Su DM, Liang M, Fu J. Chemopreventive agents induce programmed death-1-ligand 1 (PD-L1) surface expression in breast cancer cells and promote PD-L1-mediated T cell apoptosis. Mol Immunol. 2008;45:1470-1476.

40. Deng L, Liang H, Burnette B, et al. Irradiation and anti-PD-L1 treatment synergistically promote antitumor immunity in mice. J Clin Invest. 2014;124:687-695.

41. Scala S. Molecular pathways: targeting the CXCR4-CXCL12 axis-untapped potential in the tumor microenvironment. Clin Cancer Res. 2015;21:4278-4285.

42. Callea M, Albiges L, Gupta M, et al. Differential expression of PD-L1 between primary and metastatic sites in clear-cell renal cell carcinoma. Cancer Immunol Res. 2015;3:1158-1164.

43. Jilaveanu LB, Shuch B, Zito CR, et al. PD-L1 expression in clear cell renal cell carcinoma: an analysis of nephrectomy and sites of metastases. J Cancer. 2014;5: $166-172$.

44. Madore J, Vilain RE, Menzies AM, et al. PD-L1 expression in melanoma shows marked heterogeneity within and between patients: implications for anti-PD-1/ PD-L1 clinical trials. Pigment Cell Melanoma Res. 2015;28:245-253.

45. Taube JM, Klein A, Brahmer JR, et al. Association of PD-1, PD-1 ligands, and other features of the tumor immune microenvironment with response to anti-PD1 therapy. Clin Cancer Res. 2014;20:5064-5074.

46. Fusi A, Festino L, Botti G, et al. PD-L1 expression as a potential predictive biomarker. Lancet Oncol. 2015;16:1285-1287.

47. Ilie M, Long-Mira E, Bence C, et al. Comparative study of the PD-L1 status between surgically resected specimens and matched biopsies of NSCLC patients reveal major discordances: a potential issue for anti-PD-L1 therapeutic strategies. Ann Oncol. 2016;27:147-153.

48. Müller P, Rothschild SI, Arnold W, et al. Metastatic spread in patients with nonsmall cell lung cancer is associated with a reduced density of tumor-infiltrating $\mathrm{T}$ cells. Cancer Immunol Immunother. 2016;65:1-11.

49. Heskamp S, Hobo W, Molkenboer-Kuenen JD, et al. Noninvasive imaging of tumor PD-L1 expression using radiolabeled anti-PD-L1 antibodies. Cancer Res. 2015;75:2928-2936.

50. Chatterjee S, Lesniak WG, Gabrielson M, et al. A humanized antibody for imaging immune checkpoint ligand PD-L1 expression in tumors. Oncotarget. 2016;7:10215-10227.

51. Truillet C, Oh HLJ, Yeo SP, et al. Imaging PD-L1 expression with immunoPET. Bioconjug Chem. 2018;29:96-103.

52. Heskamp S, Wierstra PJ, Molkenboer-Kuenen JDM, et al. PD-L1 microSPECT/ CT imaging for longitudinal monitoring of PD-L1 expression in syngeneic and humanized mouse models for cancer. Cancer Immunol Res. 2019;7:150-161.

53. Josefsson A, Nedrow JR, Park S, et al. Imaging, biodistribution, and dosimetry of radionuclide-labeled $\mathrm{PD}-\mathrm{L} 1$ antibody in an immunocompetent mouse model of breast cancer. Cancer Res. 2016;76:472-479.

54. Nedrow JR, Josefsson A, Park S, Ranka S, Roy S, Sgouros G. Imaging of programmed cell death ligand 1: impact of protein concentration on distribution of anti-PD-L1 SPECT agents in an immunocompetent murine model of melanoma. J Nucl Med. 2017;58:1560-1566.

55. Hettich M, Braun F, Bartholoma MD, Schirmbeck R, Niedermann G. Highresolution PET imaging with therapeutic antibody-based PD-1/PD-L1 checkpoint tracers. Theranostics. 2016;6:1629-1640.

56. Jagoda EM, Vasalatiy O, Basuli F, et al. Immuno-PET imaging of the programmed cell death-1 ligand (PD-L1) using a zirconium-89 labeled therapeutic antibody, avelumab. Mol Imaging. 2019;18:1536012119829986.

57. Lesniak WG, Chatterjee S, Gabrielson M, et al. PD-L1 detection in tumors using $\left[{ }^{64} \mathrm{Cu}\right]$ atezolizumab with PET. Bioconjug Chem. 2016;27:2103-2110.
58. Rinne SS, Leitao CD, Mitran B, et al. Optimization of HER3 expression imaging using affibody molecules: influence of chelator for labeling with indium-111. Sci Rep. 2019;9:655.

59. Kikuchi M, Clump DA, Srivastava RM, et al. Preclinical immunoPET/CT imaging using Zr-89-labeled anti-PD-L1 monoclonal antibody for assessing radiation-induced PD-L1 upregulation in head and neck cancer and melanoma. OncoImmunology. 2017;6:e1329071.

60. Ehlerding EB, Lee HJ, Barnhart TE, et al. Noninvasive imaging and quantification of radiotherapy-induced PD-L1 upregulation with ${ }^{89} \mathrm{Zr}$-Df-atezolizumab. Bioconjug Chem. 2019;30:1434-1441.

61. Li D, Cheng SY, Zou SJ, et al. Immuno-PET imaging of Zr-89 labeled anti-PDL1 domain antibody. Mol Pharm. 2018;15:1674-1681.

62. Wissler HL, Ehlerding EB, Lyu Z, et al. Site-specific immuno-PET tracer to image PD-L1. Mol Pharm. 2019;16:2028-2036.

63. Broos K, Keyaerts M, Lecocq Q, et al. Non-invasive assessment of murine PDL1 levels in syngeneic tumor models by nuclear imaging with nanobody tracers. Oncotarget. 2017;8:41932-41946.

64. Lv G, Sun X, Qiu L, et al. PET imaging of tumor PD-L1 expression with a highly specific nonblocking single-domain antibody. J Nucl Med. 2020;61:117-122.

65. González Trotter DE, Meng XJ, McQuade P, et al. In vivo imaging of the programmed death ligand 1 by F-18 PET. J Nucl Med. 2017;58:1852-1857.

66. Donnelly DJ, Smith RA, Morin P, et al. Synthesis and biologic evaluation of a novel F-18-labeled adnectin as a PET radioligand for imaging PD-L1 expression. J Nucl Med. 2018;59:529-535.

67. Chatterjee S, Lesniak WG, Miller MS, et al. Rapid PD-L1 detection in tumors with PET using a highly specific peptide. Biochem Biophys Res Commun. 2017; 483:258-263.

68. De Silva RA, Kumar D, Lisok A, et al. Peptide-based Ga-68-PET radiotracer for imaging PD-L1 expression in cancer. Mol Pharm. 2018;15:3946-3952.

69. Lesniak WG, Mease RC, Chatterjee S, et al. Development of $\left[{ }^{18} \mathrm{~F}\right] \mathrm{FPy}-\mathrm{WL} 12$ as a PD-L1 specific PET imaging peptide. Mol Imaging. 2019;18:1536012119852189.

70. Muenst S, Soysal SD, Gao F, Obermann EC, Oertli D, Gillanders WE. The presence of programmed death 1 (PD-1)-positive tumor-infiltrating lymphocytes is associated with poor prognosis in human breast cancer. Breast Cancer Res Treat. 2013;139:667-676.

71. Natarajan A, Mayer AT, Xu L, Reeves RE, Gano J, Gambhir SS. Novel radiotracer for immunoPET imaging of PD-1 checkpoint expression on tumor infiltrating lymphocytes. Bioconjug Chem. 2015;26:2062-2069.

72. Cole EL, Kim J, Donnelly DJ, et al. Radiosynthesis and preclinical PET evaluation of ${ }^{89} \mathrm{Zr}$-nivolumab (BMS-936558) in healthy non-human primates. Bioorg Med Chem. 2017;25:5407-5414.

73. England CG, Jiang D, Ehlerding EB, et al. ${ }^{89} \mathrm{Zr}$-labeled nivolumab for imaging of T-cell infiltration in a humanized murine model of lung cancer. Eur J Nucl Med Mol Imaging. 2018;45:110-120.

74. England CG, Ehlerding EB, Hernandez R, et al. Preclinical pharmacokinetics and biodistribution studies of ${ }^{89} \mathrm{Zr}$-labeled pembrolizumab. J Nucl Med. 2017; 58:162-168.

75. Natarajan A, Mayer AT, Reeves RE, Nagamine CM, Gambhir SS. Development of novel immunoPET tracers to image human PD-1 checkpoint expression on tumor-infiltrating lymphocytes in a humanized mouse model. Mol Imaging Biol. 2017;19:903-914.

76. Wolchok JD, Weber JS, Maio M, et al. Four-year survival rates for patients with metastatic melanoma who received ipilimumab in phase II clinical trials. Ann Oncol. 2013;24:2174-2180.

77. Ehlerding EB, Lee HJ, Jiang D, et al. Antibody and fragment-based PET imaging of CTLA-4+ T-cells in humanized mouse models. Am J Cancer Res. 2019;9:53-63.

78. Kelly MP, Tavare R, Giurleo JT, et al. Immuno-PET detection of LAG-3 expressing intratumoral lymphocytes using the zirconium-89 radiolabeled fully human anti-LAG-3 antibody REGN3767 [abstract]. Cancer Res. 2018;78:3033.

79. Burugu S, Gao D, Leung S, Chia SK, Nielsen TO. LAG-3+ tumor infiltrating lymphocytes in breast cancer: clinical correlates and association with PD-1/PDL1+ tumors. Ann Oncol. 2017;28:2977-2984.

80. Niemeijer AN, Leung D, Huisman MC, et al. Whole body PD-1 and PD-L1 positron emission tomography in patients with non-small-cell lung cancer. Nat Commun. 2018;9:4664.

81. Bensch F, van der Veen EL, Lub-de Hooge MN, et al. ${ }^{89} \mathrm{Zr}$-atezolizumab imaging as a non-invasive approach to assess clinical response to PD-L1 blockade in cancer. Nat Med. 2018;24:1852-1858.

82. Xing Y, Chand G, Liu C, et al. Early phase I study of a ${ }^{99 \mathrm{~m} T c-l a b e l e d}$ antiprogrammed death ligand-1 (PD-L1) single-domain antibody in SPECT/CT assessment of PD-L1 expression in non-small cell lung cancer. J Nucl Med. 2019; 60:1213-1220. 